\title{
EDUCAÇÃo FÍSICA, SER PROFESSOR E PROFISSÃO DOCENTE EM QUESTÃO*
}

Zenólia Christina Figueiredo

Professora Coordenadora do Práxis - Centro de Pesquisa de Formação Inicial e Continuada em Educação Física do CEFD/UFES.

Erineusa Maria da Silva

Professora pesquisadora do Práxis - Centro de Pesquisa de Formação Inicial e Continuada em Educação Física do CEFD/UFES.

Nelson Figueiredo de Andrade Filho

Professor pesquisador do Práxis - Centro de Pesquisa de Formação Inicial e Continuada em Educação Física do CEFD/UFES.

Rosângela da Conceição Loyola

Professora pesquisadora do Práxis - Centro de Pesquisa de Formação Inicial e Continuada em Educação Física do CEFD/UFES.

Discente do Programa de Pós-Graduação em Educação Física.

Fabíola Borel Marques

Discente voluntária do Práxis - Centro de Pesquisa de Formação Inicial e Continuada em Educação Física do CEFD/UFES.

Renata Guisso de Oliveira

Bolsista UFES do Práxis - Centro de Pesquisa de Formação Inicial e Continuada em Educação Física do CEFD/UFES.

Discente do Programa de Pós-Graduação em Educação Física.

Merielle Solares de Araújo

Discente bolsista UFES do Práxis - Centro de Pesquisa de Formação Inicial e Continuada em Educação Física do CEFD/UFES.

Simone Gonçalves de Almeida

Discente voluntária do Práxis - Centro de Pesquisa de Formação Inicial e Continuada em Educação Física do CEFD/UFES.

Valéria Matedi Bufon

Discente bolsista PIBIC do Práxis - Centro de Pesquisa de Formação Inicial e Continuada em Educação Física do CEFD/UFES.

\section{Resumo}

Este estudo é qualitativo com possibilidades interpretativas. Busca compreender as ações do professor no espaço e tempo da escola, remetendo para questões da Educação Física no ensino fundamental e para a profissão docente. O lugar de investigação foi constituído por sete escolas e o trabalho delimitado em duas fases. Os sujeitos participantes da primeira fase foram diretores, corpo técnico-pedagógico, professores de outras disciplinas, alunos, pais/mães. A segunda fase focou os professores de Educação Física, a aula propriamente dita e a maneira como entendem a profissão.

Palavras-chave: Educação Física - ser professor - profissão docente

$\mathrm{E}$ ntre "velhos" dilemas e outras possibilidades interpretativas, objetivamos compreender melhor as açôes do professor no espaço e tempo da escola, remetendo-nos para questões mais amplas relacionadas com a Educação Física e com a profissão docente. Consideramos que a cultura escolar, os modos de subjetivar a Educação Física como componente curricular na educação básica e a cultura docente constituem elementos fundamentais para se entender esse objeto de estudo.

Ações é o que se refere aos modos de agir e pensar do professor: "[...] seus valores, seus compromissos, suas opções, seus desejos e vontades, seu conhecimento, seus esquemas teóricos de leitura do mundo" (PIMENTA, 2005, p. 178).

Subjetivação remete aos modos como as pessoas materializam sua subjetividade nas complexas teias de relações com a vida. Nesse estudo é compreendida como organização do

* Este artigo é fruto das investigações sobre a formação docente em Educação Física e a prática pedagógica do professor. Trata-se de um artigo ainda não publicado. Em parte, foi apresentado, sob a forma de comunicação oral, no XV Congresso Brasileiro de Ciências do Esporte (CONBRACE), realizado em Recife/PE. 
sentido e significação que aparecem de diferentes formas e em diferentes níveis no sujeito e na personalidade (MARTINEZ, 2006). Nesse caso, "só podemos compreender os significados envolvidos nesses sistemas de representação se tivermos alguma idéia sobre quais posições-de-sujeito eles produzem e como nós, como sujeitos, podemos ser posicionados em seu interior" (WOODWARD, 2000, p. 17).

Essas posições-de-sujeito são resultantes de um processo vivido pelos sujeitos e é uma forma de descrever como os mesmos acabam por adotar posições particulares: "[...] não se limita a descrever sistemas de significado, mas tenta explicar por que posições particulares são assumidas" (WOODWARD, 2000, p. 59).

Quando nos referimos a espaço e tempo, indicamos a necessidade de analisar os desafios da ação docente na perspectiva das subjetividades e identidades da Educação Física e da condição de ser professor na construção das diversas práticas da instituição escolar. O professor, ao executar sua atividade, necessita de espaço e tempo determinados, a fim de tornar lugar o espaço por ele devidamente ocupado. Lugar que não é estático, mas que relaciona, sofre e promove modificações; verificado em manifestações de palavras, sentimentos e condutas dos sujeitos correlacionados ao respectivo meio. O tempo do qual falamos é o tempo humano, "percebido e significado pela experiência humana e como é usado no transcurso dessa experiência" (VEIGA- NETO, 2006, p. 122).

Assumimos os riscos, os absurdos e as possibilidades de se investigar a e na escola (GERALDI, 2006). Há singularidades nesse cotidiano que constituem a própria cultura da instituição escolar. Entendendo que a escola produz, desenvolve e reproduz uma cultura específica, ligada à própria origem da escola como instituição.

Considera-se cultura escolar como a cultura da instituição, da comunidade, das políticas educacionais e curriculares e, prioritariamente, dos docentes como grupo social e profissional. Como o conjunto de crenças, valores, hábitos, formas de fazer as coisas e normas dominantes que influenciam e determinam o que os docentes consideram valioso no seu contexto profissional e, ainda, os modos politicamente corretos de pensar, de sentir, de atuar e de relacionar entre si (MORGADO, 2005).

\section{Práticas investigativas: ir e vir metodológico}

O lugar da pesquisa foi constituído por sete das 41 escolas de um Sistema Municipal de Ensino, subdividido em sete regiões. Após a escolha do lugar, iniciamos o trabalho de seleção dos sujeitos. A quem escutar? $\mathrm{Na}$ primeira fase da pesquisa os sujeitos do estudo foram os diretores, o corpo técnico-pedagógico, os professores de outras disciplinas, alunos, as mães ${ }^{1}$ dos alunos participantes da pesquisa. O objetivo principal na escuta desses sujeitos foi de apreender de que maneira percebem/vivem/praticam a Educação Física no espaço e tempo da escola.

Em cada uma das escolas fizemos a opção de escutar o diretor e pelo menos dois professores que compõem o corpo técnico-administrativo. Escolhemos por meio de sorteio, dois professores de outras disciplinas que compõem o currículo. Os alunos foram escolhidos aleatoriamente e abordados no espaço e tempo possíveis (desde a entrada até a saída da escola), sendo um de cada série. Os pais, mães e/ou responsáveis foram escolhidos a partir dos alunos que aceitaram realizar a entrevista.

Nessa primeira fase da investigação utilizamos a entrevista/diálogo individual e/ou coletiva com os sujeitos selecionados e registramos, por meio de fotografias, os espaços da escola, inclusive aqueles diretamente relacionados com a Educação Física.

\footnotetext{
1 Contatamos pais, mães e/ou responsáveis pelos alunos entrevistados. Entretanto, apenas as mães compareceram nas reuniões previamente agendadas por nós com fins de realização das entrevistas.
} 
Paralelamente a esse trabalho de campo, fizemos as transcrições dos diálogos e nos aproximamos dos professores de Educação Física. Conseguimos problematizar o que acontece e o que não acontece nessas escolas.

$\mathrm{Na}$ segunda fase, delimitada aos professores de Educação Física, enfocando o ser professor, os espaços e tempos das aulas propriamente ditas e a maneira como eles entendem a profissão, o trabalho foi mais intenso. Utilizamos os seguintes instrumentos: observação, diário de campo, registros fotográficos e entrevista.

\section{Os registros do Trabalho de Campo: as posições-de-sujeito e o cotidiano do ser professor de educação física}

As posições registradas apresentam diferentes modos de subjetivar a Educação Física e constituem uma cultura escolar que influi nas aulas de Educação Física que acontecem e que não acontecem nas escolas. Isso quer dizer que não é possível "olhar" para a disciplina e enxergar apenas o professor sob a ótica do isolamento profissional, ${ }^{2}$ e para a área como únicos responsáveis pela hierarquização, desvalorização ou outras tensões que têm acompanhado a Educação Física escolar ao longo dos tempos.

O diálogo inicial com os diretores, com o corpo técnico-administrativo, com professores de outras disciplinas permitiu apreender algumas posições-de-sujeito sobre a Educação Física vivenciada por ele. Buscamos ouvir experiências que ficaram registradas na memória de cada um sobre a Educação Física que tiveram nos tempos em que cursaram ensino fundamental e médio; as aulas de Educação Física, desenvolvidas nas escolas que trabalham e; o professor de Educação Física. Os diálogos foram com mães, bem como com alunos.

\footnotetext{
"O isolamento profissional é outra característica freqüente da profissão docente, que tem muito a ver com o individualismo dos professores" (MORGADO, 2005, p. 82). Ver mais a esse respeito nas páginas 82-85.
}

Conforme dito, o espaço hoje ocupado por esses sujeitos nas escolas ou entorno dela reflete determinadas posições aptas a uma melhor compreensão. Os diretores tiveram experiências diferentes com a Educação Física, apesar de terem vivido momentos históricos aproximados em função das suas idades e respectivos processos de escolarização. Os registros indicam dois pólos inversos no que diz respeito às aulas de Educação Física: um no sentido de não ter vivido nada que tivesse marcado muito e outro de ter tido experiências fortes, não com a Educação Física, mas com o esporte.

As experiências do corpo técnico-administrativo, pedagogas, diferem um pouco das experiências vividas pelos diretores e parecem ter sido positivas. Nenhuma disse ter vivido algo negativo na/com a Educação Física no ensino fundamental ou médio. Estiveram mais associadas a outras práticas corporais para além do esporte como a ginástica e jogos recreativos.

"A Educação Física é indispensável", "A Educação Física é muito importante", "Eu acho extremamente fundamental", disseram as pedagogas. Por quê? Porque dá prazer aos alunos e tira-os das drogas; porque se preocupa com a valorização do ser humano, com o comportamento, a fala, o palavreado; porque o aluno tem maior liberdade para se expressar; porque trabalha valores; porque é um momento de lazer.

Os professores das demais disciplinas trabalham com História, Geografia, Artes, Ciências, Matemática, Português e Inglês. As subjetivações construídas por esses professores a partir das suas experiências construídas na/com a Educação Física na infância e adolescência são mais diversificadas do que as construídas pelos diretores e pedagogos. Revelam um maior estranhamento a partir de questões tais como sentimento de vergonha com relação ao corpo, auto-exclusão e o trabalho de preparação física que era desenvolvido. Com relação às aulas de Educação Física 
desenvolvidas nas escolas onde trabalham, houve uma recorrência quando disseram que deveriam ser mais diretivas e que os alunos deveriam participar da mesma maneira que participam das suas disciplinas.

O diálogo com as mães e com os alunos teve como referência um roteiro diferenciado daquele utilizado nas conversas com os diretores, pedagogos e professores de outras disciplinas. Com as mães a questão comum foi sobre a experiência que tiveram com a Educação Física nos tempos em que eram alunas; a partir das outras questões, dialogamos sobre o conhecimento que tinham acerca do que os filhos aprendem nas aulas de Educação Física, se sabiam o que o professor precisa estudar na formação, quais as disciplinas consideravam mais importantes para os filhos e o que gostariam que fizessem nas aulas de Educação Física.

As conversas realizadas com os alunos foram mais próximas do roteiro utilizado para entrevista com pais e mães. Perguntamos a eles o que aprendem nas aulas de Educação Física, o que gostam de fazer, quais as disciplinas mais gostam, quais as que consideram mais importantes e se sabem o que o professor precisa estudar para ser professor. Em recorrência, os meninos gostam de jogar futebol e as meninas gostam de jogar vôlei e queimada.

Essas e outras posições identificadas foram importantes para um mapeamento inicial do vivido pelos sujeitos investigados. No entanto, mais importante foi tentar descobrir como essas experiências e posições surgem no cotidiano escolar influenciando para a construção de uma cultura escolar positiva e/ou negativa junto aos alunos, relacionada às aulas de Educação Física, à profissão e ao ser professor. Essa é a interpretação que buscamos desenvolver mais adiante.

A segunda fase da pesquisa focou olhares no ser professor de Educação Física e nos espaços e tempos das aulas e na maneira como eles entendem a profissão. Fizemos a imersão em duas das sete escolas em que realizamos entrevistas. Dialogamos com os professores de Educação Física e acompanhamos suas aulas por meio da observação por um período aproximado de três meses.

Optamos por conviver com e no espaço e tempo do vespertino. Na primeira escola entrevistamos um professor e uma professora atuantes naquele turno, bem como acompanhamos as aulas das turmas de quinta, sétima e oitava séries ${ }^{3}$ do ensino fundamental. $\mathrm{Na}$ segunda escola acompanhamos um único professor atuante nas séries iniciais e finais do ensino fundamental. Decidimos observar as quintas, sétimas e oitavas séries, conforme ocorrera na primeira escola. Encerrada essa etapa de diálogos e observações, organizamos os registros, esquematizados por série/data $\mathrm{e}$ apresentamos cópias aos professores e à professora para leitura, análise e retorno pessoal em uma reunião previamente agendada. Após uma semana da entrega dos registros, retornamos à escola a fim de que comentassem sobre as próprias práticas, relatando seus sentimentos, inquietações e posicionamentos.

\section{A primeira imersão: a Escola de Ensino Fundamental "São José"}

Essa é a escola em que a professora Cíntia e o professor Gilmar trabalham. Cíntia concluiu a Licenciatura Plena em Educação Física em 1991 e, Gilmar, 1981.

A professora trabalhava nessa escola por um mês e sua permanência se estenderia por um ano. Por isso, acreditava que não seria viável intervir ou modificar a organização das aulas sem a certeza de continuar, além de desarticular uma estrutura aparentemente funcional da escola.

\footnotetext{
3 Determinamos como critério de observação assistir às aulas de turmas e horários coincidentes. Nem todas as aulas eram ministradas para as mesmas séries. Havia, por exemplo, $5^{\mathrm{a}}$ série $\mathrm{C}$ com $6^{\mathrm{a}}$ série $\mathrm{A}$.

4 Todos os nomes utilizados nesse relatório de pesquisa são fictícios.
} 
O professor Gilmar atua há 25 anos na área escolar; desses, os últimos quatro anos são dedicados a docência na escola a qual investigamos. Apesar de ser descontraído e comunicativo, confessou ter dificuldades em ceder no que diz respeito ao conteúdo de suas aulas; quando precisa, procura convencer o outro a favor de suas idéias. Assim, demonstra uma segurança e um domínio das turmas.

As observações ocorreram em várias circunstâncias, algumas sem que pudéssemos prever. A priori, acompanhamos as aulas ministradas em quadra, as quais eram coordenadas pelos dois professores entrevistados, que se responsabilizavam por duas turmas simultaneamente, ocupando o mesmo espaço e tempo.

Em determinado momento, a professora Cíntia que se encontrava incomodada com as dinâmicas das aulas coletivas, decidiu que suas aulas ocorreriam separadas das turmas do professor Gilmar. Por isso, presenciamos aulas ora em sala, ora em quadra, resolvendo a cada observação onde (sala ou quadra) poderia haver maior contribuição no que se relaciona à prática pedagógica do professor de Educação Física escolar.

Ao contrapor as entrevistas com nossas observações foi possível entender que a fala expressa retrata um desejo de ser ou de fazer; entretanto, na prática pedagógica pudemos aproximar dos acontecimentos imprevisíveis e improvisados do cotidiano.

O período que permanecemos na Escola de Ensino Fundamental "São José" foi suficiente para compreender a rotina estabelecida e, talvez, automatizada por todos que a constituem. Nas primeiras observações previstas não pudemos acompanhar as aulas por diversos motivos: sumiço da chave da sala de materiais, dedetização, etc.

Durante as aulas foi nítida a presença dominante do esporte. De acordo com os professores, essa prática não estava direcionada a eficiência, mas sim à saúde físico-mental, integração/socialização. Os professores pautavam suas aulas no ensinamento de funda- mentos e execução dos jogos. Tal prática permite aos alunos o aprendizado mais parcial, com constantes correções dos professores quanto à execução de determinados fundamentos. Quando era oportunizada a escolha do que fazer, as aulas eram livres e os alunos, geralmente, optam por modalidades esportivas, tais como futebol, voleibol ou handebol.

De acordo com a dinâmica das aulas seria possível imaginar que esta proporcionaria a socialização e desenvolvimento dos indivíduos, mediante as vivências predominantemente em grupo, com caráter criativo/espontâneo. Todavia, nesse estudo durante o jogo esportivo os próprios alunos excluíam seus colegas, atitude justificada pelo limitado grau de habilidade de alguns. Ocorria, também, a autoexclusão daquele aluno que não participava, julgando-se incapaz de executar as manobras de determinado esporte.

Ao acompanhar as aulas em quadra observamos uma rotina bastante internalizada. Os alunos vinham de suas salas com o professor. $\mathrm{Na}$ quadra se acomodavam na mini-arquibancada, situada em uma das laterais, configurando-se dois grupos: um composto por meninos e outro por meninas. Ao realizarem as atividades a separação ocorria da mesma forma. Em alguns instantes, esta disposição era orientada pelo professor, em outros se tratava de uma atitude tomada por parte dos alunos.

\section{A segunda imersão: a Escola de Ensino Fundamental "Maria Maia"}

$\mathrm{Na}$ escola "Maria Maia" trabalha o professor Daniel há sete meses. Ele concluiu seu curso de graduação no ano de 1989 e, desde então, trabalhou com treinamento desportivo, atuando como técnico de um time de basquete, e há quatro anos trabalha na área escolar. Quanto à segurança na atuação profissional, Daniel, às vezes, se sente seguro. Seu trabalho é pautado na obrigatoriedade e o aluno que não participa da aula obtém nota baixa na avaliação. 
O período em que permanecemos nessa Escola foi o suficiente para observar alguns conflitos pessoais e profissionais. Daniel disse que o curto tempo de atuação na escola é um fator que dificulta seu trabalho. Outra reclamação é a respeito da indisciplina dos alunos. Devido à localização periférica da instituição disse que eles mandam na escola não obedecendo nem as regras nem a autoridade dos professores.

Quanto ao conteúdo a ser trabalhado propôs aos alunos todas as modalidades esportivas coletivas. Entretanto, ressaltou que os alunos queriam apenas futebol e vôlei e que isso o desestimulou um pouco. De acordo com Daniel "[...] faz aula quem quer, ele não obriga [...], mas que ao final do bimestre passa trabalhos escritos para quem não fez aula prática".

Daniel nos informou que dividiu as modalidades por bimestres e a cada mês ele trocaria de modalidade. No período de observação assistimos o final da prática do basquete, um mês de handebol e o último bloco de atividades que foi o vôlei e o futebol juntos.

\section{Os modos de subjetivar a Educação Física}

Buscamos compreender os cotidianos investigados a partir da idéia de que os modos como os sujeitos constroem seus significados sobre a Educação Física podem contribuir para a produção de uma cultura que influencia, diretamente, na Educação Física que se vive/pratica em cada uma das escolas e, particularmente, nas duas escolas observadas.

Nos registros do vivido pelos diretores e pedagogas, percebemos significações confusas atribuídas à Educação Física que podem repercutir no modo como os alunos vivem e percebem as aulas de Educação Física. As mais comum são as significações de confundir Educação Física e Esporte. As menos comuns dizem respeito à falta de clareza sobre o objeto de ensino, o que faz com que atribuam à Educação Física o trabalho de formação de valores (disciplina, respeito ao próximo, etc.), de reforçar conteúdos de outras disciplinas nas aulas de Educação Física e de ocupar os tempos livres dos alunos quando da ausência de professor.

Também significativo para uma interpretação de nossa parte é a posição das pedagogas quanto ao processo ensino e aprendizagem na Educação Física. Foi central e alvo de elogios o fato de o professor saber lidar bem com os alunos, cumprir o horário das aulas, controlá-los em quadra e desenvolver as aulas sem maiores transtornos para a coordenação da escola.

Já parte dos professores das demais disciplinas expressa posições enfáticas quanto ao trabalho desenvolvido pela Educação Física no sentido de que as aulas deveriam ser mais diretivas e os alunos deveriam ser cobrados a participar. As mães não sabem o que os filhos aprendem nas aulas de Educação Física e chegaram a expressar posição de que não aprendem nada. Os alunos que se identificam com as aulas gostam de praticar esportes e os que não se identificam ficam sentados.

Essas e outras posições e ações confusas no entorno da Educação Física identificadas nas entrevistas desses sujeitos parecem estar relacionadas com significações que hierarquizam as disciplinas e que, ocultamente, reconhecem e priorizam a Matemática e o Português como as mais importantes e, também, como as que os alunos mais gostam. Ao contrário das expectativas iniciais e de pesquisas realizadas na área, a Educação Física não esteve entre as disciplinas que mais gostam, nem entre as disciplinas que mais consideram importantes.

Há de se considerar que as posições dos diretores, pedagogas, professores das demais disciplinas e mães, de alguma forma, se materializaram na Educação Física das escolas quando: a) da recusa de um aluno em participar das aulas por não gostar ou por não considerar importante; $b$ ) da prioridade de certos saberes escolares em detrimento de outros; c) 
da valorização do saber utilitário; d) do estereótipo esportista atribuído ao professor de Educação Física.

Nas observações das aulas percebemos algumas ações intrínsecas e extrínsecas à Educação Física propriamente dita, ou seja, algumas pertencem aos modos de ser professor e as próprias subjetivações da área, outras aos modos que os sujeitos da escola significam a Educação Física no cotidiano.

Os professores de Educação Física carregam histórias de vida, formações, vitórias/fracassos que essencialmente os diferem e, conseqüentemente, possuem modos particulares de subjetivar. ${ }^{5}$

Ficou evidente que um deles, em função do tempo de magistério, acredita que já contribuiu, ao seu modo, com a Educação Física, ao passo que a professora acredita na diferenciação pedagógica e qualificação do ser professor.

Há dois modos de agir bastante diferenciados: enquanto o professor demonstra o movimento dos fundamentos do basquetebol na tentativa de fazer com que os alunos o reproduzissem, a professora busca utilizar uma forma mais dialógica, colocando uma situação problema para os alunos pensarem sobre.

Ambos compartilhavam o mesmo espaço e tempo na execução de suas aulas, ou seja, duas turmas razoavelmente numerosas sob a coordenação simultânea dos profissionais. Ressaltamos que o professor atuava naquela comunidade há muitos anos e a professora atuava naquele contexto há menos de um ano.

Em que pese essa subjetivação ser de ordem particular está em diálogo permanente com questões objetivas como condições de trabalho, descaso com a escola pública etc., e nessa relação dialética percebe-se a conformação de situações recorrentes passíveis inclusive de delimitação. É o que faz Nóvoa (2000) ao teorizar sobre a profissão docente. $\mathrm{O}$ autor afirma que independente da área pertencente, a carreira profissional é delimitada por uma organização de seqüências, as quais não se estabelecem necessariamente em uma ordem rígida e definitiva.
Devido à diferença desse convívio na escola tanto com os profissionais quanto com os alunos, em muitos momentos restava à professora duas opções: a adaptação aos modos do professor ou o embate. Dois modos de subjetivar que não se adequaram. Assim, as aulas de Educação Física passaram a ser realizadas separadamente e como toda atividade pressupõe um espaço adequado a sua prática, surgiu a dificuldade (VEIGA-NETO, 2006). Onde estaria um dos professores e sua turma, quando a quadra estivesse sendo utilizada por outro professor?

Sem muita alternativa tentou-se a utilização de um pátio, próximo das janelas das salas de aula. Confrontando essa situ(ação) de intervenção da pedagoga com sua posição na entrevista de que "A Educação Física é indispensável”, há no mínimo, uma contradição. Deixa-nos a impressão de que sua indispensabilidade está relacionada à organização da escola e secundária na relação de espaço e tempo com as outras disciplinas.

Apesar dessa situação de utilização da quadra sob a forma de rodízio ter incomodado os professores, indicamos como positivo o fato de ambos terem que replanejar as suas aulas para além do esporte. A professora iniciou um trabalho no refeitório da escola com o conteúdo ginástica e o professor com yoga.

Mesmo com essa iniciativa "forçada", constatamos uma Educação Física com ênfase no esporte, favorecendo o domínio do espaço e das ações dos alunos considerados mais habilidosos, ainda que consideremos a preocupação da professora quanto à inclusão dos alunos discriminados nas aulas. Tomamos como base as providências da professora Cíntia, que por várias vezes, dialoga com seus alunos estimulando a integração.

Assim, percebemos outros modos de significar a aula por parte dos professores, ora em prol da inclusão, ora da exclusão ou mesmo da auto-exclusão, quando os próprios alunos desistiam de participar das aulas por não apreciar a modalidade esportiva, por não 
sentir capacidade em executar tal atividade ou por não se sentir aceito na atividade. Essa exclusão e/ou auto-exclusão, quase sempre esteve ligada à questão de gênero.

A separação entre os sexos feminino e masculino, em que pese a maioria das turmas serem mistas, tem sido uma constante nas atividades que ocorrem nas aulas de Educação Física. Percebemos que meninos geralmente executavam as atividades somente com meninos; e as meninas, por sua vez, procediam da mesma forma.

Em alguns momentos tal separação ocorria a partir do próprio professor. Entretanto, ficou evidente que a potencialização do afastamento entre alunos do sexo feminino e masculino são, também, decorrentes deles próprios no cotidiano escolar. Confirmamos esse movimento quando os alunos chegavam à quadra acomodando-se na arquibancada, no ritual das filas antes do início das aulas e para o canto do Hino Nacional ou na utilização da quadra no tempo do recreio. Tudo determinado ou influenciado pela condição de gênero. ${ }^{6}$

As formas de subjetivar a condição de gênero pelos professores e por alunos entrevistados a partir das suas experiências na/com a

6 Segundo Lauretis, citado por Silva (1989), gênero não é apenas uma construção sócio-cultural, mas também um sistema de representação de todos os níveis. Isso porque conforme ela diz, "a construção de gênero é o produto e o processo tanto da representação quanto da autorepresentação". Nessa perspectiva, a concepção de gênero leva as pessoas inseridas socialmente a atribuírem significado às relações entre o homem e a mulher "pelas representações do outro e auto-representações do masculino e do feminino". Uma forma de contribuirmos para a construção de uma sociedade mais igualitária passa pela discussão de gênero nas escolas, a partir da formação permanente de professores/ as no sentido de desnaturalizar papéis sociais, introduzindo práticas educativas que tenham como meta a igualdade de oportunidades nas relações de gênero (equidade) e o fim das práticas discriminatórias e sexistas.
Educação Física, tanto quando há separação por sexo nas atividades por parte do professor ou por uma decisão dos próprios alunos, relaciona-se (em maior ou menor grau) a como tais relações foram construídas e representadas historicamente pela/na escola. Uma das funções da educação tradicional, de forma geral, e das instituições de forma específica, foi exatamente apresentar condutas diferenciadas para os indivíduos de sexos diferentes.

Percebemos nas aulas formas diferenciadas de subjetivar as relações sociais de gênero que se estabeleciam nas aulas: desde a falta de habilidade em lidar com a questão na medida em que tratavam a questão como se a mesma fosse algo dado - natural dos sexos - portanto, não cabendo nenhuma interferência, até o reforço das separações de gênero.

$\mathrm{Na}$ Escola de Ensino Fundamental "Maria Maia” o professor de Educação Física, assim como os professores da primeira escola, carrega consigo histórias de vida, vitórias/fracassos e, conseqüentemente, possui modos particulares de ser professor.

Parte das recorrências registradas no cotidiano da Escola "São José" se repete. Entretanto, houve ações diferenciadas e ressignificadas no cotidiano dessa escola. Um exemplo foi a ausência constante do professor nas aulas, bem como os consecutivos adiantamentos de aulas das turmas que haviam ficado sem outras disciplinas devido à falta de algum professor. Nesse caso, Daniel unia duas ou três turmas ao mesmo tempo para que as aulas dos alunos terminassem após o recreio.

As vezes que se encontrava em quadra, o professor encostava-se à lateral observando os alunos e, em alguns momentos, marcava falta nos jogos, atuando como se fosse um árbitro. A prática regular era a que Daniel entregava a bola aos alunos e se dirigia para a lateral da quadra. Por vários momentos os alunos reclamavam com ele porque não queriam jogar basquete, mas ele mantinha a proposta e dizia que só quando terminasse o tempo daquele esporte é que mudaria de modalidade. 
Observamos duas significações bastante interligadas ao ser professor e à aula propriamente dita. A ação de não intervir nas aulas, ao mesmo tempo em que indica certo desinvestimento da carreira, também pode indicar um modo subjetivo de não atribuir significado às aulas de Educação Física.

Nessa escola, o lugar da Educação Física é "ocupado" por parte dos alunos e das alunas. Todos saem da sala de aula em direção à quadra, mas nem todos participam efetivamente. Eles ficam pelo meio do caminho, no pátio, na sala da coordenação conversando ou andando pela escola. Os que chegam à quadra se reúnem e, geralmente, "tiram" par ou ímpar para escolher os times e para ver quem fica esperando para jogar. Curioso e diferentemente da primeira escola é que na maioria das vezes, os times são mistos. Isso pode indicar uma forma de subjetivar as relações de gênero de forma diferenciada da escola São José, talvez pelo meio em que vivem, ou até por uma habilidade maior das meninas nos jogos.

Apesar de apresentar uma cultura diferenciada da outra escola no que diz respeito às condições de gênero, podendo-se perceber um maior respeito à participação durante as aulas, independente do sexo, ainda persiste a divisão entre meninos e meninas em outros momentos como de utilização da quadra no tempo do recreio.

O problema quanto à prática esportiva separada parece ser minimizada por alguns momentos coletivos. Há registros, inclusive, de interação entre os alunos e alunas da oitava série com um aluno, declaradamente, homossexual.

Durante os jogos esses alunos atuam como "juízes" das partidas, recorrendo ao professor somente no caso de dúvidas. Eles se organizam quanto à entrada e saída dos times da quadra. Enquanto uns jogam os outros aguardam na lateral conversando sobre o jogo, sobre namoros, brincando e cantando funk.

Consideramos que os significados atribuídos à Educação Física estão intrinsecamente relacionados aos modos como ela vem sendo praticada pelos alunos e alunas. É possível verificar influências externas a partir do que conseguimos apreender do diálogo com os outros profissionais, mas não há como negar a formação de posições negativas a respeito da Educação Física produzidas pelo não trabalho do professor.

Afirmamos, então, que as posições e ações apreendidas produzem e reproduzem significados que definem uma cultura escolar específica e voltada à Educação Física. Posições essas, muitas vezes, construídas mais a partir das próprias experiências corporais dos sujeitos que vivem a escola do que em experiências construídas no pensar, no sentir, no atuar e no relacionar.

\section{"Velhos" dilemas... outras problemáticas}

Se retomarmos o processo da investigação em busca de tentar compreender melhor as ações do professor no espaço e tempo da escola e as questões relacionadas com a disciplina Educação Física e com a profissão docente, podemos considerar que os "velhos" dilemas podem e devem ser tomados em processo contínuo de estudo.

Não é demais pensar nas seguintes problemáticas: a Educação Física permanece com dificuldades de tornar lugar o espaço por ela ocupado no ensino fundamental? De que maneira se produz e reproduz experiências negativas na e com a Educação Física? De que maneira as posições-de-sujeitos que vivem o currículo constituem diferentes modos de subjetivar a Educação Física? Como as ações desses sujeitos constituem uma cultura escolar que influi, diretamente, nas aulas de Educação Física que acontecem ou não nessas escolas? É possível "olhar" para a disciplina e enxergar apenas o professor e para área como únicos responsáveis pela hierarquização, desvalorização ou outras tensões que têm acompanhado a Educação Física escolar ao longo dos tempos? Essas e outras problemáticas podem ser avaliadas como "velhos" dilemas. Entretanto, ainda não podem ser consideradas como resolvidas. 
Parece haver um "igual" nas ações dos professores de Educação Física e na produção da área que é "diferente". Por exemplo: não se "rola a bola" da mesma maneira; o não fazer do professor não é o mesmo; as maneiras de a Educação Física não ocupar o seu lugar são diferentes; as posições-de-sujeito influenciam a Educação Física de diversas formas.

\section{On Physical Education, being a teacher and the teaching profession}

\begin{abstract}
This is a qualitative study with interpretative possibilities. It aims at understanding teacher actions in the space and time of the school environment, leading to discussion issues on primary school physical education and the teaching profession. Research was conducted in seven schools and work was organized in two phases. Participating subjects on the first phase were school directors, technicians, pedagogues, teachers of other subjects, students and their parents. Phase two focused on physical education teachers, the class in itself, and the way teachers understand their profession.

Keywords: Physical Education - being a teacher - the teaching profession
\end{abstract}

\section{Educación Física, Ser Profesor y Profesión docente es cuestión}

\section{Resumen}

Este estudio es cualitativo con posibilidades de entendimiento y búsqueda de comprender las acciones del profesor en el espacio y tiempo de la escuela, remitiendo a cuestiones de Educación Física en la enseñanza primaria y para la profesión docente. El lugar de investigación fue construido por siete escuelas y el trabajo delimitado en dos fases. Los sujetos participantes de la primera fase fueron directores, cuerpo técnico- pedagógico, profesores de otras asignaturas, alumnos, padres/madres. La segunda fase enfocó a los profesores de Educación Física, la clase propiamente dicha y la manera como entienden la profesión.

Palabras-clave: Educación Física - ser profesor - profesión del profesor

\section{Referências}

GERALDI, Corinta Maria Grisolia. Desafios da pesquisa no cotidiano da/na escola. In: GARCIA, Regina Leite; ZACCUR, Edwi- ges (Orgs.). Cotidiano e diferentes saberes. Rio de Janeiro: DP\&A, 2006. p. 181-222.

MARTINEZ, Albertina Mitjans. A perspectiva histórico-cultural da subjetividade: sua significação para o trabalho com alunos deficientes. In: SILVA, Aída Maria Monteiro et al. (Orgs.). Novas subjetividades, currículo, docência e questôes pedagógicas na perspectiva da inclusão social. Encontro Nacional de Didática e Prática de ensino. Recife: ENDIPE, 2006. p. 372-373.

MORGADO, José Carlos. Currículo e profissionalidade docente. Portugal: Porto, 2005.

NÓVOA, Antonio. Os professores e as histórias da sua vida. In: NÓVOA, Antonio (Org.). Vidas de professores. Portugal: Porto, 2000. p.11-30.

PIMENTA, Selma Garrido; ANASTASIOU, Lea Maria das Graças Camargos. Docência no ensino superior. 2. ed. São Paulo: Cortez, 2005. p. 178-179.

VEIGA-NETO, Alfredo. Memória, tempos e cotidianos. In: GARCIA, Regina Leite; ZACCUR, Edwiges (Orgs). Cotidiano e diferentes saberes. Rio de janeiro: DP\&A, 2006. p. 111-124.

WOODWARD, Kathryn. Identidade e diferença: uma introdução teórica e conceitual. In: SILVA, Tomaz Tadeu da (Org.). Identidade e diferença: a perspectiva dos estudos culturais. Petrópolis: Vozes, 2000. p. 7-72.

\section{Recebido: 29 de fevereiro de 2008}

Aprovado: 3 de maio de 2008

\section{Endereço para correspondência}

zenolia@npd.ufes.br 